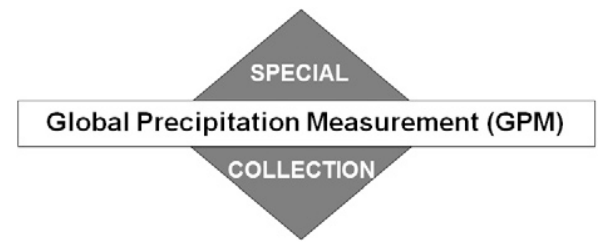

\title{
Ground Validation of Surface Snowfall Algorithm in GPM Dual-Frequency Precipitation Radar
}

\author{
Minda Le AND V. CHANDRASEKAR \\ Colorado State University, Fort Collins, Colorado
}

(Manuscript received 19 June 2018, in final form 31 January 2019)

\begin{abstract}
Extensive evaluations have been performed on the dual-frequency classification module in the Global Precipitation Mission (GPM) Dual-Frequency Precipitation Radar (DPR) level-2 algorithm. Both rain type classification and melting-layer detection continue to show promising results in the validations. Surface snowfall identification is a feature newly added in the classification module to the recently released version to provide a surface snowfall flag for each qualified vertical profile. This algorithm is developed upon vertical features of $\mathrm{Ku}$ - and $\mathrm{Ka}$-band reflectivity and dual-frequency ratio from DPR. In this paper, we validate this surface snowfall identification algorithm with ground radars including NEXRAD, NASA Polarimetric Radar (NPOL), and CSU-CHILL radar during concurrent precipitation events and GPM validation campaign Olympic Mountain Experiment (OLYMPEX). Other ground truth such as Precipitation Imaging Package (PIP) and ground report is also included in the validation. Based on 16 validation cases in the years 2014-18, the average match ratio between surface snowfall flag from space radar and ground radar is around $87.8 \%$. Promising agreements are achieved with different validation sources. Algorithm limitation and potential improvement are discussed.
\end{abstract}

\section{Introduction}

The Global Precipitation Measurement (GPM) mission is the successor of the successful Tropical Rainfall Measuring Mission (TRMM). The GPM Core Observatory satellite was launched in February 2014 with a DualFrequency Precipitation Radar (DPR) on board for the first time. Compared to TRMM, which is a tropical mission, GPM provides 3D dual-frequency observations of precipitation on a global scale from $65^{\circ} \mathrm{N}$ to $65^{\circ} \mathrm{S}$, covering the cold area of Earth.

Detection of falling snow is an important objective of the GPM mission, because it accounts for a significant fraction of precipitation in Earth's hydrological cycle, especially at the mid-high latitudes (Hou et al. 2014). Extensive research has been conducted on studying snow microphysical properties and snow retrievals from multiple sensors (Wood et al. 2014; Heymsfield et al. 2018; Casella et al. 2017; von Lerber et al. 2018). In recent years, several GPM validation campaigns such as the GPM Cold Season Precipitation Measurement (GCPEX) and the Olympic Mountain Experiment

Corresponding author: Dr. Minda Le, leminda@colostate.edu.
(OLYMPEX; OLYMPEX 2015) are focused on improving the understanding and detecting of falling snow (Skofronick-Jackson et al. 2015; Houze et al. 2017).

DPR on board the GPM has matched vertical profile of $\mathrm{Ku}$ and $\mathrm{Ka}$ band at each valid footprint. The dualfrequency ratio DFRm (difference between $\mathrm{Ku}$ and $\mathrm{Ka}$ reflectivity) is a very important measurement heavily used in the dual-frequency classification module to perform rain type classification and melting-layer detection (Le and Chandrasekar 2013). Using a similar philosophy, Le et al. (2017) developed an algorithm to identify surface snowfall at each DPR matched footprint. It uses vertical features of dual-frequency reflectivity profiles of different precipitation types. These features include reflectivity amplitude, dual-frequency ratio, slope with respect to height, and storm-top height. An effective "snow index" is then built that can separate surface snowfall from rain at a $97 \%$ success rate. Brief algorithm descriptions are available in section 2. The algorithm provides a surface snowfall flag (1 or 0 product) at each valid DPR Ku- and Ka-band matched footprint.

Le et al. (2017) showed initial qualitative evaluations of the algorithm with promising results when compared 
to some of the Next Generation Weather Radars (NEXRAD; or WSR-88D). In this paper, we focus on performing more extensive ground validations in both qualitative and quantitative manner with NEXRAD, NASA Polarimetric Radar (NPOL), and CSU-CHILL radar in the last three years of 2014-18. Fourteen validation cases are selected under different geographical conditions, different seasons of the year, and different surface types. For those cases occurred during the OLYMPEX campaign, we enhanced the validation results (Chandrasekar and Le 2017) together with site ground reports and Precipitation Imaging Package (PIP) images. A match ratio is calculated between surface snowfall product and ground radar retrievals (Bechini and Chandrasekar 2015) for each validation case. Averaged match ratio for 16 cases is about $87.8 \%$. Some of the discussions lead to the limitation of the algorithm under shallow precipitation situations.

In section 2, we briefly describe the surface snowfall identification algorithm. In section 3, the validation performances are evaluated for cases under different geological conditions including flatland, lake, mountain, and coastline. Statistical analysis is performed. Section 4 is the algorithm limitation and improvements. The summary and conclusions are in section 5 .

\section{Brief algorithm description}

An algorithm is developed for GPM DPR inner swath (before scan pattern change) to identify snowfall at the surface, not aloft. The algorithm details can be found in Le et al. (2017). This surface snowfall flag is a Boolean variable 0 or 1 , where " 1 " means surface snowfall, while " 0 " means no surface snowfall; that is, it could be rain, wet snow, graupel, or hail. The algorithm is mainly based on vertical features of both radar reflectivity profiles at $\mathrm{Ku}$ and $\mathrm{Ka}$ band and also the DFRm (in $\mathrm{dB}$ ). The slope of the DFRm with respect to height and the maximum value of reflectivity at $\mathrm{Ku}$ band along the profile are the two major components of the snow index. To further separate rain and snow profiles, the storm-top height information is included. The definition of snow index is

$$
\text { Snow index }(\mathrm{SI})=\frac{\operatorname{mean}\left[\operatorname{abs}\left(\mathrm{DFRm}_{\text {slope }}\right)\right]}{\mathrm{Zmku}_{\max } \times \text { Storm_top_height }} .
$$

The DFRm slope is in the unit of $\mathrm{dB} \mathrm{km}^{-1}$, and Zmku_max is in dBZ. The Storm_top_height represents the altitude of storm top in kilometers. The components in calculating (1) are normalized. Large-scale statistical analysis is performed on DPR profiles with preknowledge of different precipitation types. We found that the

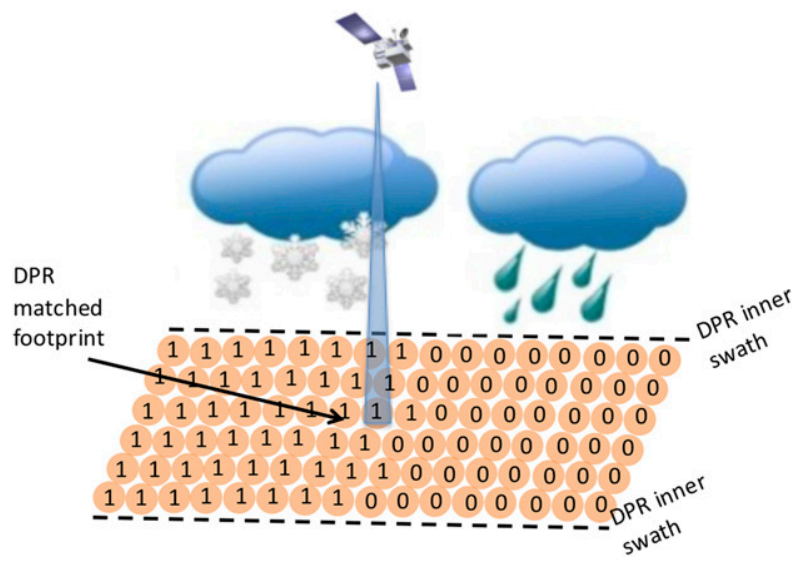

FIG. 1. A cartoon illustration of "flagSurfaceSnowfall" product in the GPM DPR level-2 algorithm. Orange circles are DPR matched footprint; " 1 " represents snow and " 0 " represents no snow. Number of circles in the plot does not represent number of footprints in the real DPR inner swath.

snow index (SI) value is larger for most snow profiles than for rain. At around $97 \%$ of the cumulative density function (CDF) curve, a snow index threshold equal to 17 can separate snow and rain profiles. In other words, $97 \%$ of snow profiles have SI $>17$, while $97 \%$ of rain profiles have $\mathrm{SI} \leq 17$. A snow flag is generated using the thresholds of the snow index as well as other auxiliary information such as $0^{\circ} \mathrm{C}$ isotherm and clutter-free height but only as constraints. This surface snowfall flag is a " 0 " or " 1 " product, where " 0 " represents no snow and " 1 " represents snow. In the GPM DPR level-2 algorithm, this flag is named as "flagSurfaceSnowfall" and is currently available in the experimental module. The algorithm details can be found in Le et al. (2017).

Figure 1 is a cartoon illustration of the "flagSurfaceSnowfall" product in the GPM DPR level-2 algorithm. In the plot, at each matched DPR footprint, a 0 or 1 value is given when precipitation is observed. It needs to be noticed that in the current version (version 5) of the DPR products this surface snowfall flag is available only at DPR inner swath (where dual-frequency measurements are available). Thus the performance of the algorithm is evaluated in this work within the DPR inner-swath data. After radar scan pattern change, this flag will be extended to full DPR swath.

\section{Validation activities and performance evaluation}

As an indispensable part of the GPM mission, ground validation helps to develop the radar retrieval algorithms by providing insight into the physical and statistical basis of precipitation. Among various validation equipment, ground-based dual-polarization radar has 
TABLE 1. Information on snow validation cases in years of 2014-18.

\begin{tabular}{lllc}
\hline \multicolumn{1}{c}{ Radar } & \multicolumn{1}{c}{ Date } & Surface type & $\begin{array}{r}\text { GPM DPR } \\
\text { orbit No. }\end{array}$ \\
\hline KILX & 22 Dec 2014 & Flatland & 4638 \\
KOKX & 9 Jan 2015 & Coastline & 4914 \\
KEAX & 31 Jan 2015 & Flatland & 5263 \\
KBUF & 14 Mar 2015 & Lake & 5908 \\
KIWX & 23 Mar 2015 & Lake & 6052 \\
NPOL & 14 Nov 2015 & Coastline & 9722 \\
KDVN & 21 Nov 2015 & Flatland & 9828 \\
NPOL & 3 Dec 2015 & Coastline & 10019 \\
KAKQ & 5 Feb 2016 & Coastline & 11011 \\
KAPX & 25 Feb 2016 & Lake & 11319 \\
KARX & 24 Mar 2016 & Flatland & 11755 \\
CSU-CHILL & 16 Apr 2016 & Mountain & 12119 \\
KGRR & 18 Nov 2017 & Lake & 21160 \\
KCLE & 14 Dec 2017 & Lake & 21554 \\
KOTX & 20 Dec 2017 & Flatland & 21648 \\
KDOX & 4 Jan 2018 & Coastline & 21882 \\
\hline
\end{tabular}

shown great advantages to conduct precipitation observation over a wide area in a relatively short time span. Therefore, ground radar is always a key component in all the validation field experiments (Chandrasekar et al. 2008).

The validation radars used in this study are NEXRAD, NPOL, and CSU-CHILL radar. NEXRAD is a network of 160 high-resolution S-band dual-polarization ground radars operated by the U.S. National Oceanic and Atmospheric Administration (NOAA). NEXRAD has good coverage in the United States, which makes it easier to find overlapped precipitation events with DPR. All radar sites in the lower 48 United States are given a four-letter call number that starts with "K." NPOL is NASA's premier mobile S-band dual-polarization weather radar. It is located near NASA's Wallops Flight Facility in Newark, Maryland, when not being deployed for GPM field campaigns. Validation case with the NPOL observation is taken during the OLYMPEX campaign in this study. CSU-CHILL radar is an advanced, transportable dual-polarized dual-wavelength ( $\mathrm{S}$ and $\mathrm{X}$ band) weather radar system located in Greeley, Colorado.

Validation cases are carefully selected within the years 2014-18 to demonstrate algorithm stability under different geophysical conditions including mountain, lake, flatland, and coastline and under different seasons of the year. Table 1 illustrates a list of radar and precipitation events we have done validation with.

NEXRAD KOKX, KAKQ, and KDOX are located at coastal areas where local climate is complicated by coastlines and marine boundary layer stratus. The validation case with NPOL during the OLYMPEX campaign is explicitly selected for validation at coastline.

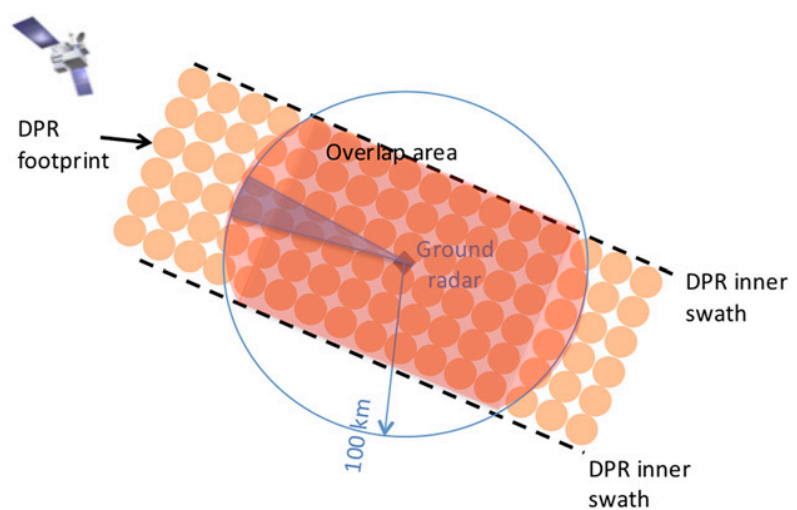

FIG. 2. A cartoon illustration to depict the approach performing quantitative validation between surface snowfall identification algorithm and ground radar hydrometeor types. Orange circles are DPR matched footprints. Blue circle represents $100-\mathrm{km}$ range of ground radar observation. Red areas are the overlap region between DPR inner swath and ground radar lowest PPI scan.

NEXRAD KIWX, KAPX, KGRR, and KCLE are close to the Great Lakes. Severe snow events are reported every year in that area due to the lake effect. CSU-CHILL radar in Colorado is to the east of the Rocky Mountains, where weather conditions can change dramatically within hours. Snow events are chosen from November to April of the year. The cases that occurred in March and April, when surface temperature is higher than during winter, are selected to demonstrate the algorithm's capability to detect surface snowfall using information other than temperature.

In the validation process, first precipitation events that are simultaneously (in a 10-min time window) captured by both GPM DPR and ground radar are selected. Then hydrometeor type is classified using ground radar observations for choosing snow events. Third, surface snowfall identification algorithm is applied to DPR observations during these events. Finally, comparisons are done between hydrometeor type results from two radars. This algorithm is only for detecting snowfall toward the surface, not aloft. The algorithm used to perform hydrometeor identification for ground radar is described in Bechini and Chandrasekar (2015). During validation campaign as OLYMPEX, we have more ground truth such as PIP image and ground reports to add to the confidence of comparison.

Besides qualitative comparison, we further enhance the evaluations with quantitative analysis. Figure 2 is an illustration that shows how quantitative analysis is performed in this study. Solid orange circles for DPR inner swath (between two black dashed lines) are the $\mathrm{Ku}$ - and Ka-band matched footprints. The big blue circle is the $100-\mathrm{km}$-range circle for ground radar at the lowest elevation angle (around $0.5^{\circ}$ ). The red area is the overlap 
area between DPR swath and ground radar observation. The match ratio between DPR and ground radar is calculated within this red area. Whenever the DPR footprint has a valid 0 or 1 value from the surface snowfall flag, we search the ground radar hydrometeor type at the closest latitude and longitude data point. When the snow flag is 1 (surface snowfall exists), we consider hydrometeor types of dendrite (DN; in Bechini and Chandrasekar 2015), crystal (CR), and dry snow (DS) from ground radar to be a match. When the snow flag is 0 (surface snowfall does not exist), the other hydrometeor types from the ground radar identification algorithm are considered a match. The hydrometeor type identified from the ground radar is summarized in Table 2 [details can be found in Bechini and Chandrasekar (2015)]. The match ratio is calculated as

$$
\text { Match Ratio }=\frac{\text { No. of match points }}{\text { No. of valid points of DPR }} .
$$

If the match ratio equals 1 , it means all DPR footprints can find a match of snow/no snow with ground radar. It needs to be noted that the match ratio is calculated when both DPR and ground radar have precipitation [or valid in (2)]. DPR has limited detectability due to its attenuation at higher frequencies compared to the ground radar. It is normal that valid DPR points are less than the ground radar.

\section{a. Validation with NEXRAD KDVN-Flatland case}

Figure 3 illustrates a snowstorm observed by both GPM DPR and NEXRAD KDVN on 21 November 2015 near Davenport, Iowa. DPR flew over the KDVN location at 0830:59 UTC with the orbit number of 9828. Figure 3a shows KDVN radar S-band reflectivity at plan position indicator (PPI) scan of $0.46^{\circ}$. The time of the scan starts at 0832:59 UTC. The time difference within $10 \mathrm{~min}$ is considered coincidence in this study, while the time difference for this case is only around $2 \mathrm{~min}$. The dashed black line is the right boundary of the DPR inner swath, and the solid black line is the right boundary for the DPR outer swath. The red solid line is the nadir scan of DPR. Two black circles are the 50- and $100-\mathrm{km}$ range of the KDVN radar, whose location is represented by a black diamond. Reflectivity for most of the scan is around or below $30 \mathrm{dBZ}$. Figure $3 \mathrm{~b}$ shows the hydrometeor type identification (ID) for the scan in Fig. 3a using the hydrometeor type identification algorithm described in Bechini and Chandrasekar (2015). This algorithm is a fuzzy logic-based method to retrieve hydrometeor types for dual-polarization radar at each range bin. The abbreviations illustrated in Fig. $3 \mathrm{~b}$ can be found in Table 2. The whole scan is dominated by crystal
TABLE 2. Meaning of abbreviation used for ground radar hydrometeor identification.

\begin{tabular}{clcl}
\hline \hline Abbreviation & \multicolumn{1}{c}{ Type } & Abbreviation & \multicolumn{1}{c}{ Type } \\
\hline DN & Dendrite & RH & Rain and hail \\
CR & Crystal & HR & Heavy rain \\
DS & Dry snow & RA & Rain \\
WS & Wet snow & DR & Drizzle \\
GR & Graupel & LD & Large drop \\
HA & Hail & ND & No data \\
\hline
\end{tabular}

and dry snow with a bit of drizzle and rain to the east and south of KDVN. Figure $3 \mathrm{c}$ is the DPR reflectivity of $\mathrm{Ku}$ band at $2-\mathrm{km}$ height. In this study, the DPR plots at certain height are all with respect to the ellipsoid. Compared to Fig. 3a, part of the signal is below DPR minimum detectable reflectivity $(18 \mathrm{~dB} Z$ for $\mathrm{Ku}$ band). The surface snowfall identification algorithm is applied to the DPR inner swath and the result is shown in Fig. 3d. Dark green represents snow and light green is for no snow. Except for a few points, the whole part of the scan is classified as surface snowfall. The common area between DPR inner swath and ground radar is to the left of dashed line and within the $100-\mathrm{km}$ circle of KDVN. Comparing Figs. $3 \mathrm{~b}$ and $3 \mathrm{~d}$ in this common area, for almost all the locations where the snow flag shows snowfall, ground radar has corresponding crystal or dry snow types. The match ratio calculated in the common area is 0.99 using the equation described in (2).

\section{b. Validation with NEXRAD KCLE-Lake case}

KCLE is one of the NEXRAD located at Cleveland, Ohio, near the Great Lakes region, where lake-effect snow is typical during the winter season. A snow event is observed by both GPM DPR and KCLE on 14 December 2017 at the shoreline of Lake Erie. The GPM DPR orbit number is 21554 and it is over the KCLE site at 0320:19 UTC. Similar to Fig. 3, KCLE S-band reflectivity PPI scan at the lowest elevation angle $\left(0.49^{\circ}\right)$ is illustrated in Fig. 4a. The scan start time is 0320:45 UTC. The observations from space radar and ground radar are only seconds apart. The solid black line is the left boundary of the DPR outer swath. Black dashed lines are the boundaries of the DPR inner swath. In Fig. 4b, hydrometeor type from ground radar shows most of the scan is covered by crystal and dry snow, with a small area of scattered rain identified to the west of the radar. DPR reflectivity at $2-\mathrm{km}$ height is in Fig. $4 \mathrm{c}$ and the corresponding snow flag is illustrated in Fig. 4d. The region between KCLE 100-km range (big circle) and the DPR inner swath is pretty much overlapped. Wherever there is a valid snow flag, we can 
(a)

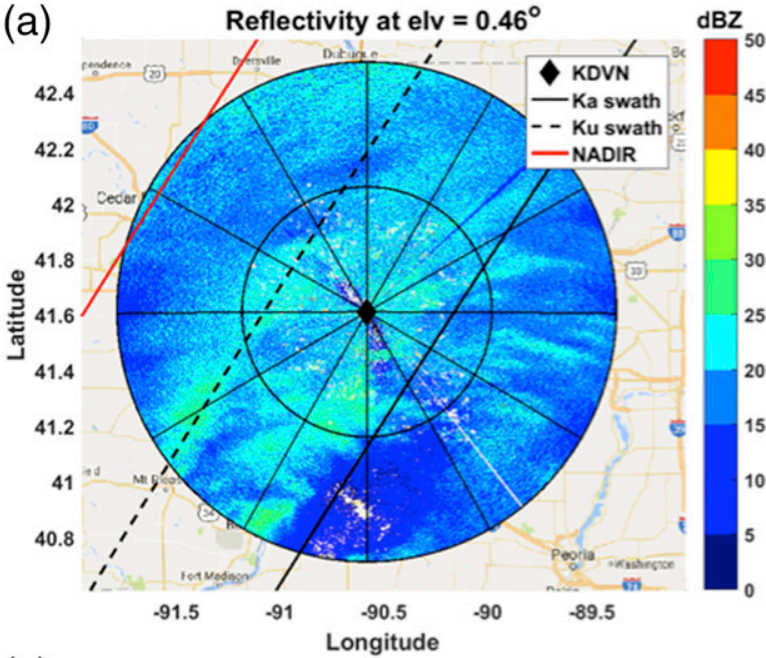

(c)

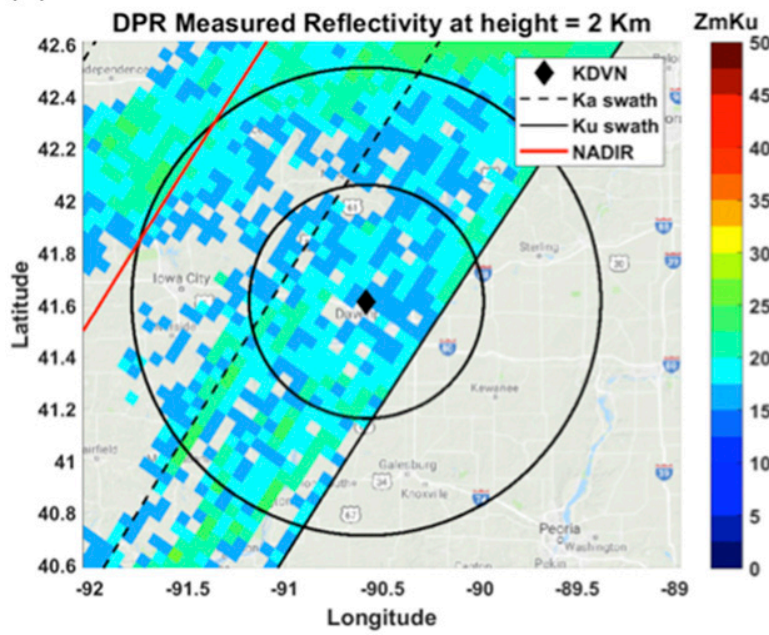

(b)

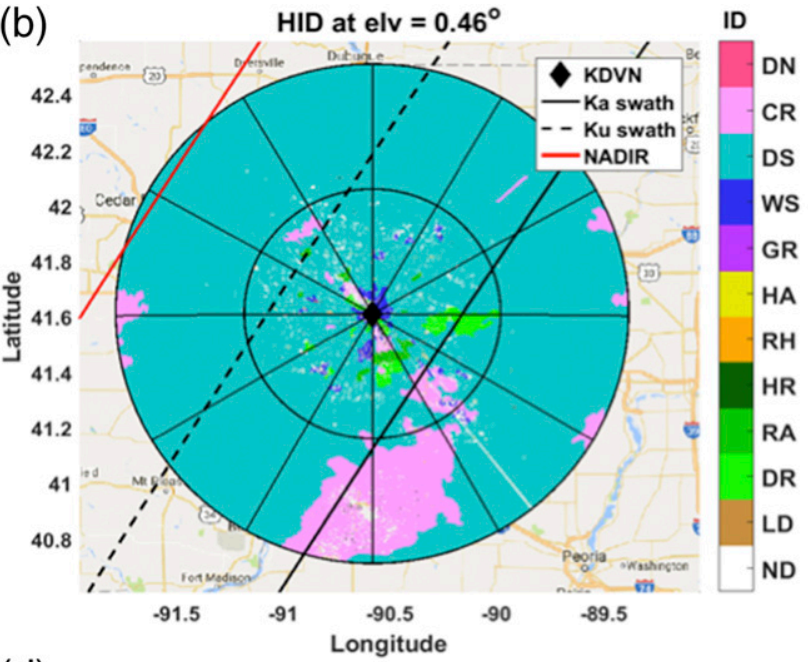

(d)

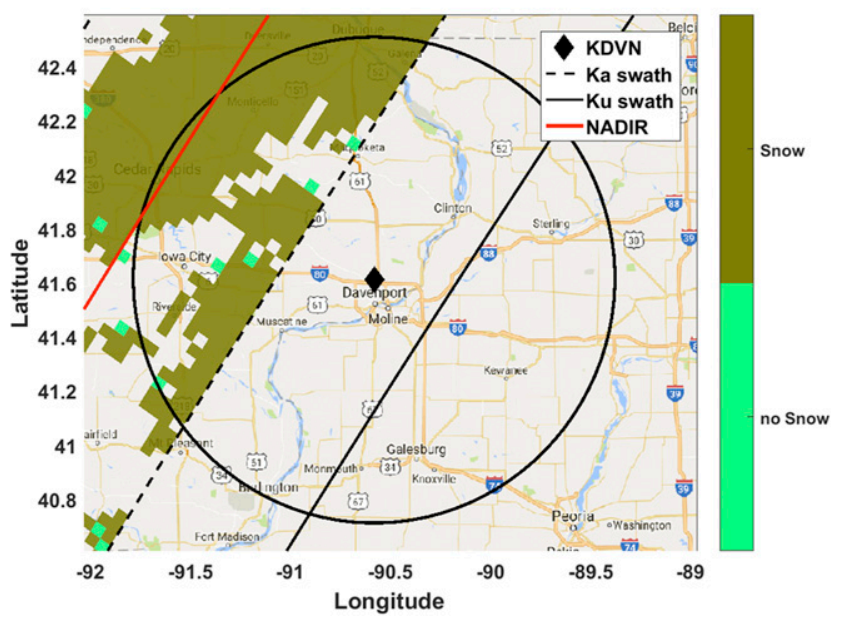

FIG. 3. Precipitation event observed by both GPM DPR overpass 9828 and KDVN radar at Davenport on 21 Nov 2015 . Red solid line is the nadir scan of DPR. Black solid line is DPR outer swath. Black dashed line is for DPR inner swath (before scan pattern change). Two black circles are 50- and 100-km range of KDVN, whose location is represented by a black diamond. (a) KDVN radar S-band reflectivity at PPI elevation angle of $0.46^{\circ}$. (b) Hydrometeor type for the scan in (a). (c) DPR reflectivity at outer swath at 2-km height. (d) Surface snowfall flag. Dark green represents snow and light green is for not snow.

find a match of either crystal or dry snow from the ground radar. The exception is for several points close to DPR nadir, where ground radar identifies drizzle. Overall, this case demonstrates the robustness of the algorithm near the Great Lakes region with the match ratio calculated to be as high as 0.97 .

\section{c. Validation with CSU-CHILL-Mountain case}

The CSU-CHILL National Weather Radar Facility is located in Greeley just $60 \mathrm{~km}$ away to the east of the Rocky Mountains. Snow is the main if not the only precipitation type during the winter and even spring season. GPM DPR captured a snow precipitation at around 1413:00 UTC 16 April 2016 over the CSUCHILL radar site. The DPR orbit number is 12119 .
Figure 5 shows the details of the event. Figure $5 \mathrm{a}$ illustrates the CSU-CHILL radar reflectivity at elevation angle of $0.88^{\circ}$ at 1413:53 UTC. The scan from CSUCHILL is around $1 \mathrm{~min}$ later than the time DPR flew over. The PPI scan was restricted to the south section because of the Rocky Mountains. Two solid black lines are the boundaries of the DPR outer swath, while two dashed black lines are for the inner swath. The two circles are 100- and 50-km range to CSU-CHILL. In Fig. 5b, hydrometeor type shows "dry snow" for most of the section of that scan. DPR reflectivity at Ku band at $3 \mathrm{~km}$ is plotted in Fig. 5c. Snowfall flag is illustrated in Fig. 5d showing "snow" for almost the entire DPR inner swath within the 100-km range of the CSU-CHILL radar. Comparing Figs. 5b and 5d, although the overlap 
(a)

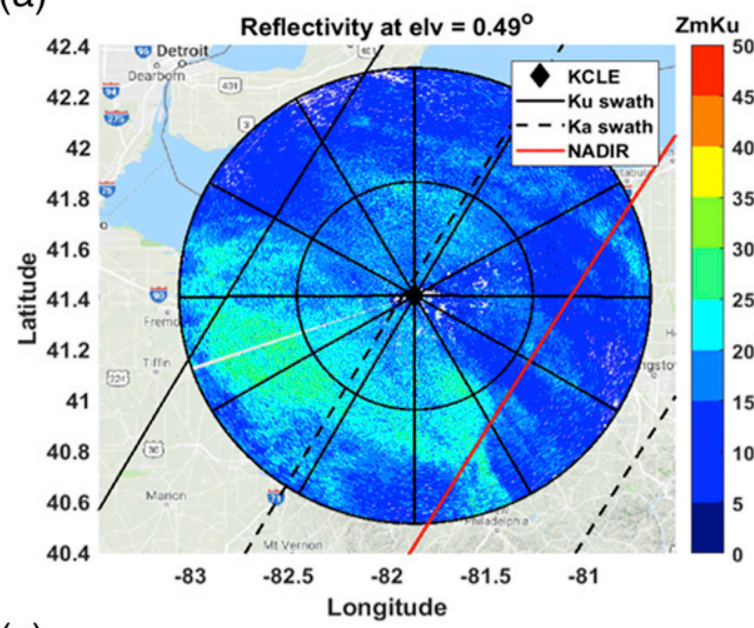

(c)

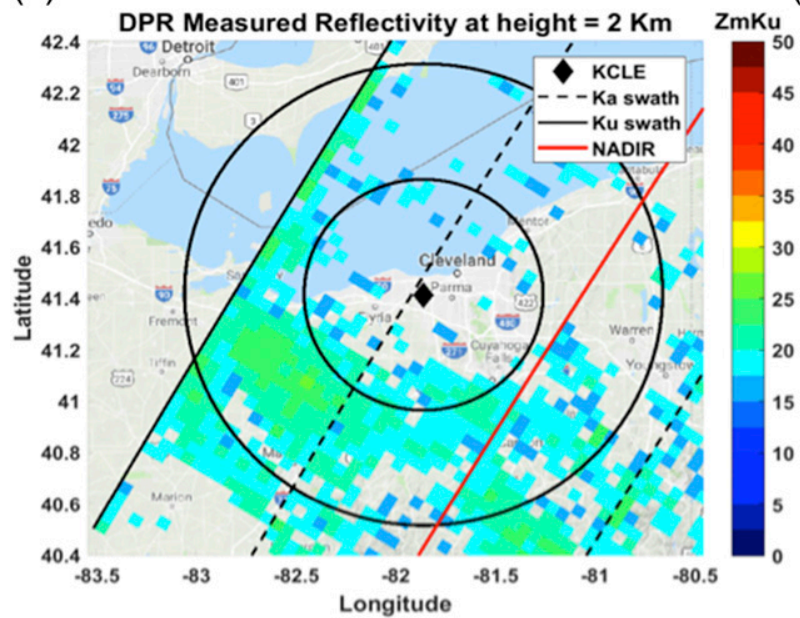

(b)

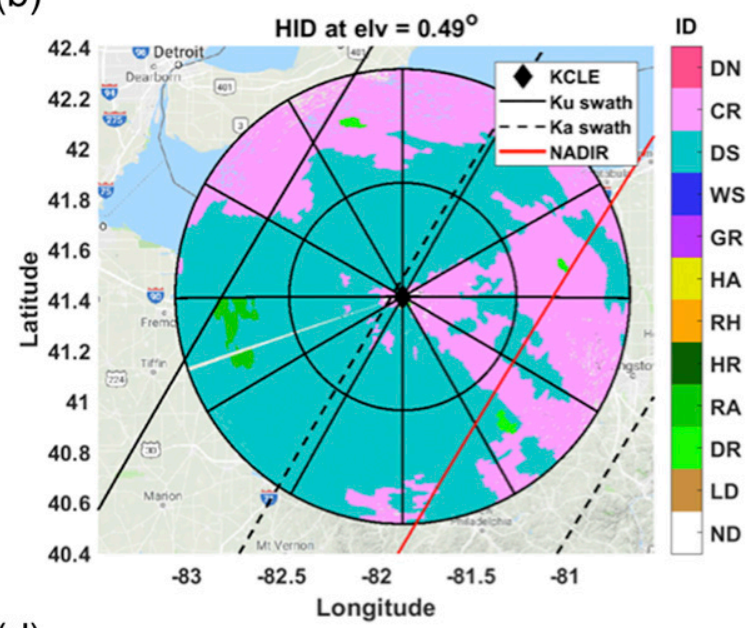

(d)

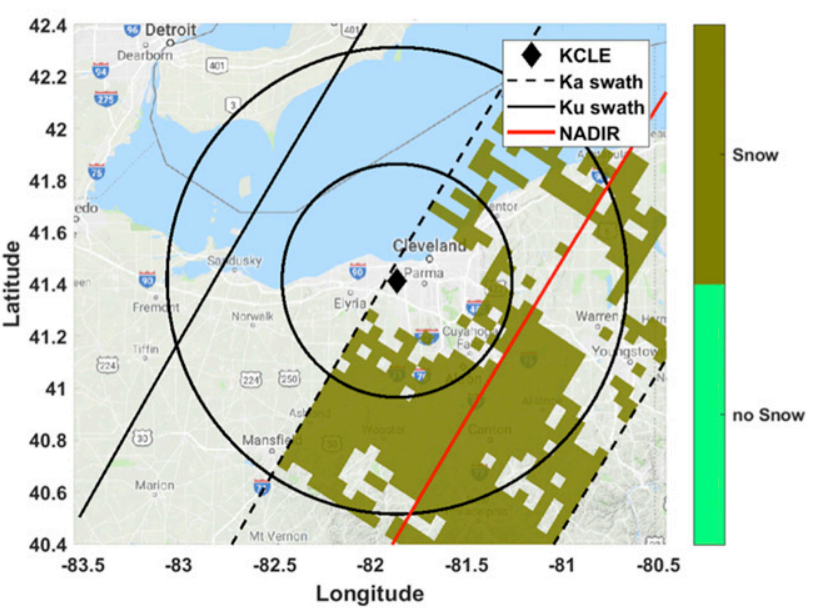

FIG. 4. Precipitation event observed by both GPM DPR overpass 21554 and KCLE radar at Cleveland on 14 Dec 2017. The meaning of the lines is the same as in Fig. 3. (a) KCLE radar S-band reflectivity at PPI elevation angle of $0.49^{\circ}$. (b) Hydrometeor type for the scan in (a). (c) DPR reflectivity at outer swath at 2-km height. (d) Surface snowfall flag. Dark green represents snow and light green is for not snow.

section is relatively small, the two snowfall detection algorithms from space and ground radar show a match ratio of 0.98 .

\section{d. Validation with NPOL-Coastline case}

OLYMPEX was a NASA field campaign, which took place on the Olympic Peninsula of Washington State from November 2015 to February 2016. One of the goals of the campaign was to collect detailed atmospheric measurements that will be used to evaluate satellite algorithms for rainfall and snowfall detection. As shown in Fig. 6, different kinds of validation equipment including ground radar, airborne radar, and ground-based passive devices are available as an observational network in the campaign that eases our validation (Houze et al. 2017).

Ground radar used in this validation work is the NASA NPOL. Figure 7 shows a precipitation event detected by both NPOL and GPM DPR orbit 10019 on 3 December 2015 during the OLYMPEX campaign. DPR flew over the NPOL site at 1523:32 UTC. Figure 7a is NPOL S-band reflectivity at elevation of $0.48^{\circ}$ with start time of 1519:09 UTC. As in other validation cases, the black solid line is the left boundary of the DPR outer swath. Two black dashed lines are boundaries of the DPR inner swath. The big black circle is the $100-\mathrm{km}$ range of the NPOL. Part of the scan is blocked by the Olympic Mountains on the northeast side. Figure $7 \mathrm{~b}$ shows the hydrometeor type for the scan in Fig. 7a using the algorithm in Bechini and Chandrasekar (2015). Unlike the cases we illustrated before, the hydrometeor type for most of the NPOL scan is classified as rain except for the northeast part, where crystal is present. Figure $7 \mathrm{c}$ is the $\mathrm{Ku}$-band reflectivity at $2 \mathrm{~km}$ for DPR overpass. The surface snowfall identification 
(a)

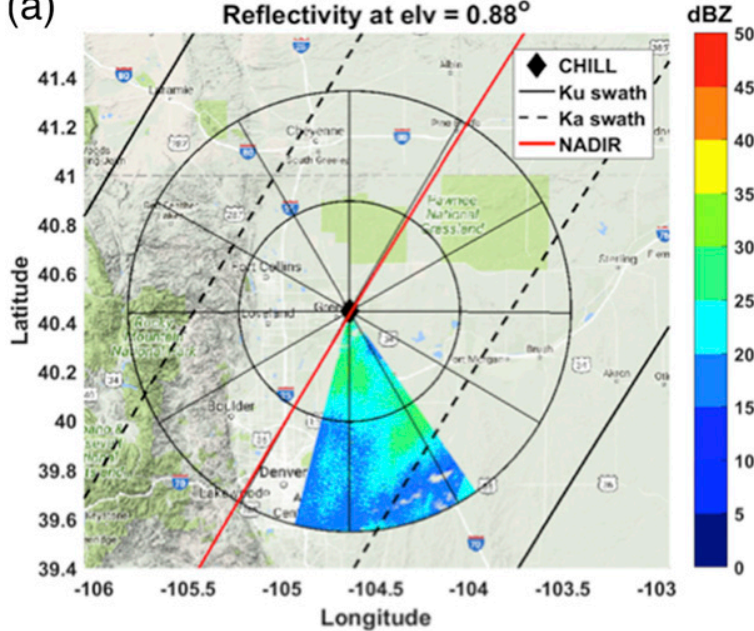

(c)

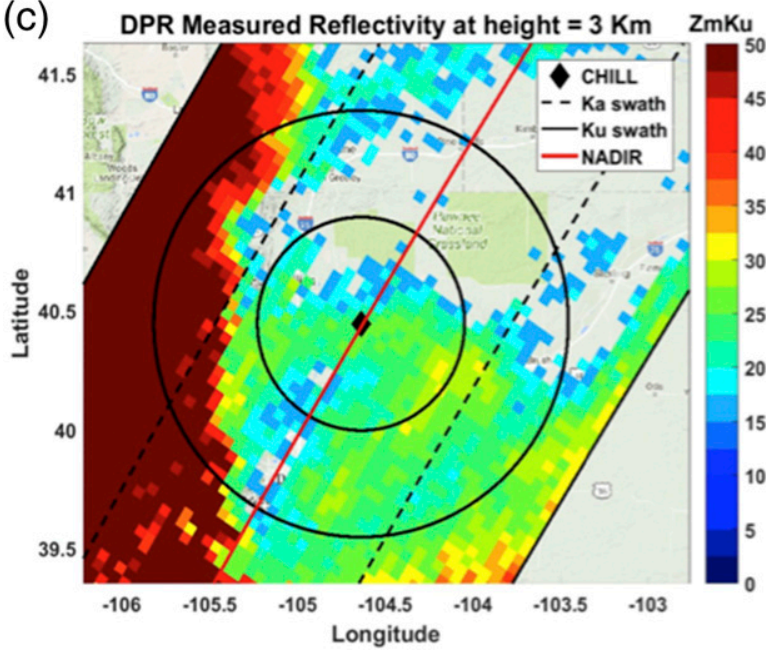

(b)

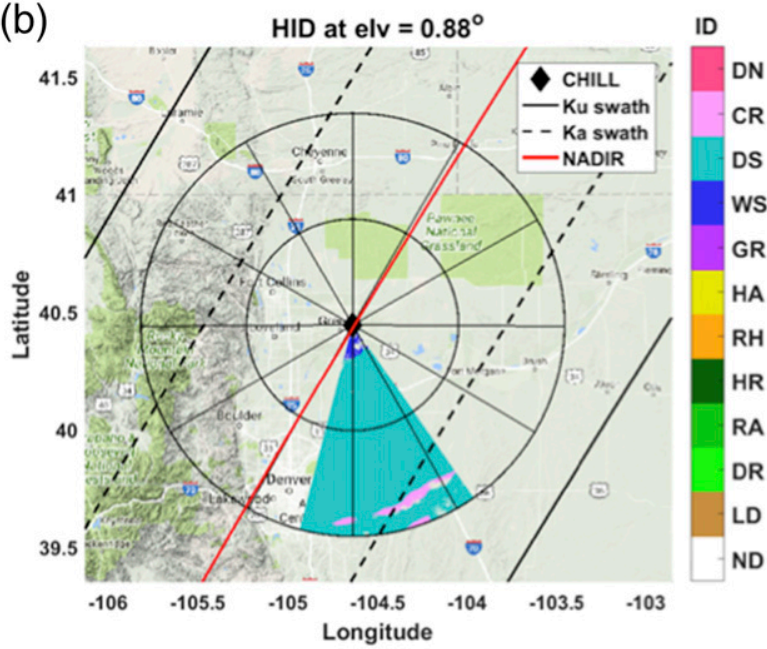

(d)

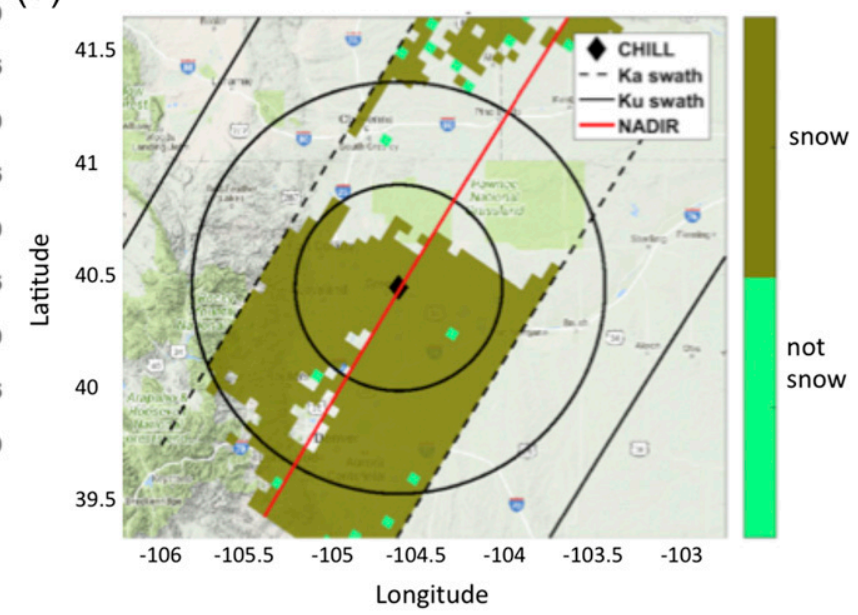

FIG. 5. Precipitation event observed by both GPM DPR overpass 12119 and CSU-CHILL radar at Greeley on 16 Apr 2016. The meaning of the lines is the same as in Fig. 3. (a) CHILL radar S-band reflectivity at PPI elevation of $0.88^{\circ}$. Scan start time is $1413: 53$ UTC. (b) Hydrometeor type for the scan in (a). (c) DPR reflectivity at outer swath at $3 \mathrm{~km}$. (d) Surface snowfall flag.

algorithm is applied to the DPR inner swath and the snow flag is shown in Fig. 7d. According to the snow flag result, surface snowfall presents at the northeast side of the scan and well matches the location from Fig. 7b, although the area showing snow is a bit wider for the DPR. The match ratio is around 0.91 for this case.

Besides radar, there are other ground-based validation tools available in the campaign. A PIP imager is located at Hurricane Ridge, shown as a blue triangle in Fig. $7 \mathrm{~d}$. The PIP is a new ground-based precipitation imaging instrument that uses a high-speed camera and advanced processing software to image individual hydrometeors, measure hydrometeor size distributions, track individual hydrometeors, and discriminate liquid, mixed, and frozen (e.g., snow) precipitation. This measurement is important because it is the only ground measurement obtained on the side of the Olympic Mountains. Luckily, the location of the PIP is within the DPR inner swath for the validation case. Figure 7e shows the plot of precipitation rates from the PIP at Hurricane Ridge during the whole day of 3 December 2015. Around $1.5 \mathrm{~mm} \mathrm{~h}^{-1}$ snowfall rate was detected by the PIP imager at the time DPR flew by. From the PIP image, it looks like both snow and rain stay mixed for a pretty extended period of time. However, the surface snowfall flag is a Boolean product, where there is no "snow/not snow" mixed choice. When surface snowfall exists, the flag captures it and gives the 1 value. In this case, it demonstrates that this surface snowfall flag can at least capture the snow part even when it could be mixed by rain.

\section{e. Quantitative analysis}

The match ratio is calculated for each validation cases in Table 1 . The equation we use to calculate the match 


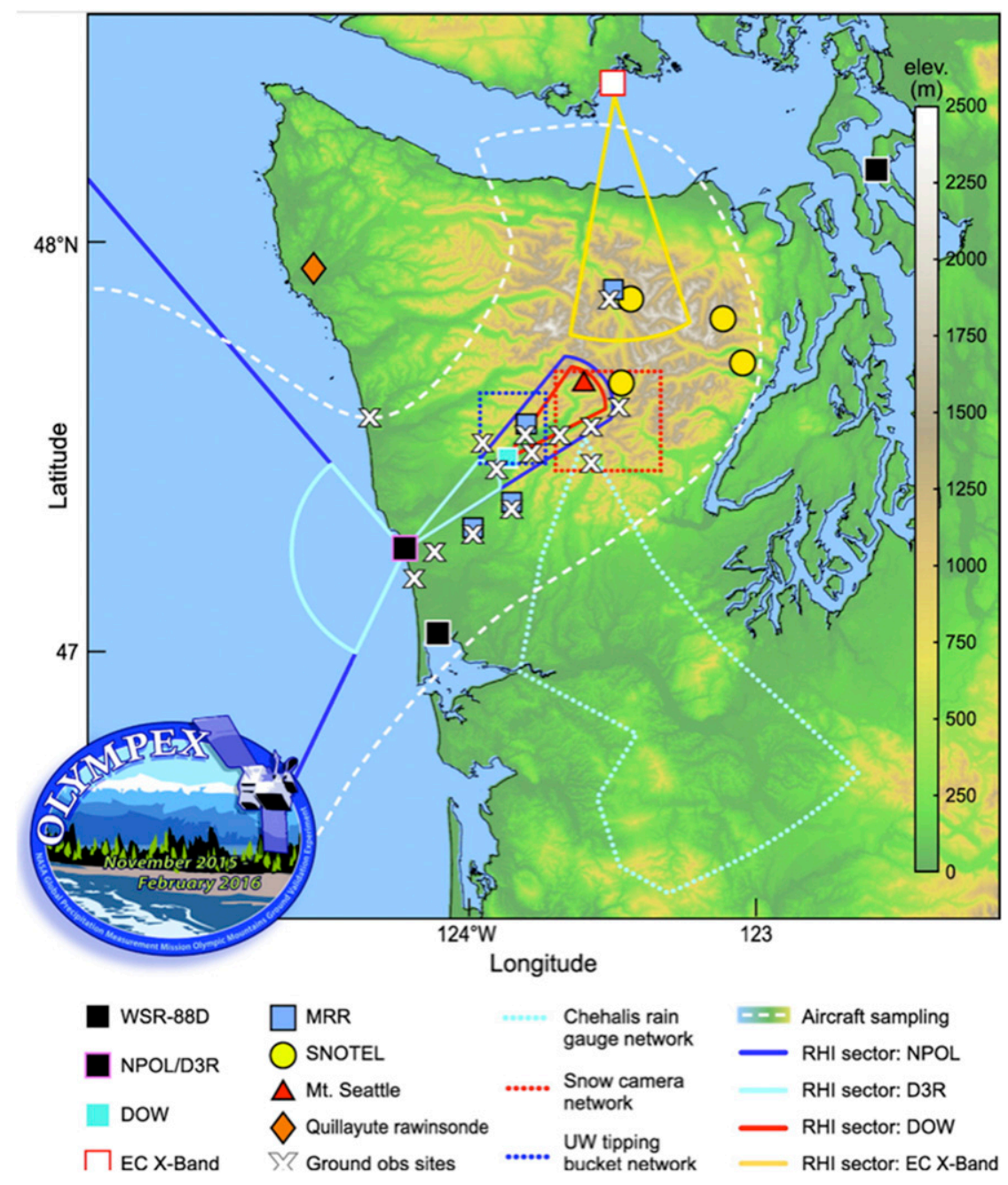

FIG. 6. The OLYMPEX observational network (image source: https://pmm.nasa.gov/ OLYMPEX).

ratio is described in (2). Figure 8 shows the results of all 16 cases from the recent years. The validation radars are NPOL, NEXRAD, and CSU-CHILL. Validation cases are chosen from different surface types, including five from flatland, five from lake, five from coastline, and one from mountain. In the figure, 11 out of 16 cases have the match ratio above $85 \%$. The rest are all above $70 \%$. In Table 3, we illustrate the total number of data points in comparison and the averaged match ratio for each surface type. Lake and mountain cases have a higher match ratio above $90 \%$, although there is only 1 available mountain case in this study so far. The averaged ratio for flatland is the lowest but still above $85 \%$. The averaged match ratio among all 16 cases is $87.8 \%$, which is a promising result. Precipitation observed by DPR and KOTX and KARX radar are flatland cases with relative low match ratio, 0.7 and 0.84 , respectively. These two cases have a common feature: precipitation with low bright band (lower than $1 \mathrm{~km}$ ), where surface snowfall algorithm has limited ability to capture the information at this low altitude. We will discuss this in detail in section 4. All lake cases used in this validation are around the Great Lakes area, where lake-effect snow dominates the precipitation events in winter. There is less occurrence of low brightband precipitation events, which explains the higher match ratio.

\section{Algorithm limitations and potential improvement}

Figure 9 illustrates a precipitation event during OLYMPEX on 14 November 2015 in Washington. Figure 9a shows the Ku-band reflectivity from DPR orbit 9722 at 1303:38 UTC. DPR has a nice overlap 
(a)

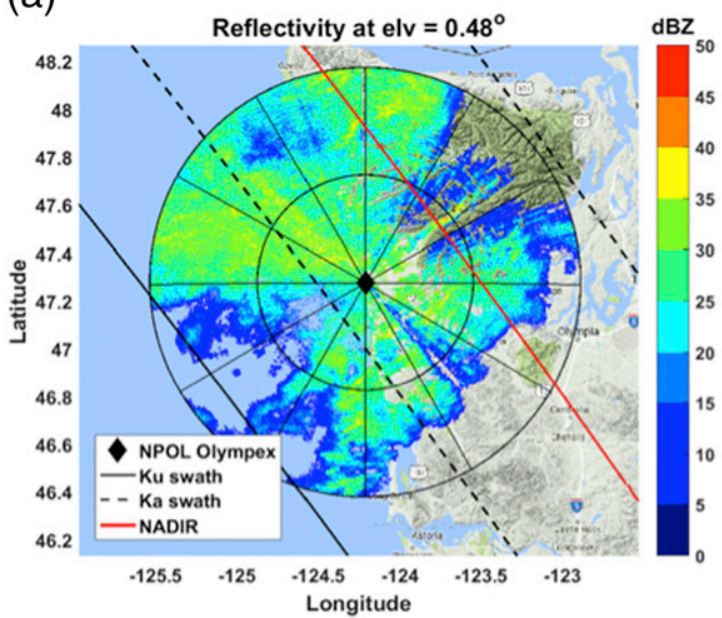

(c)

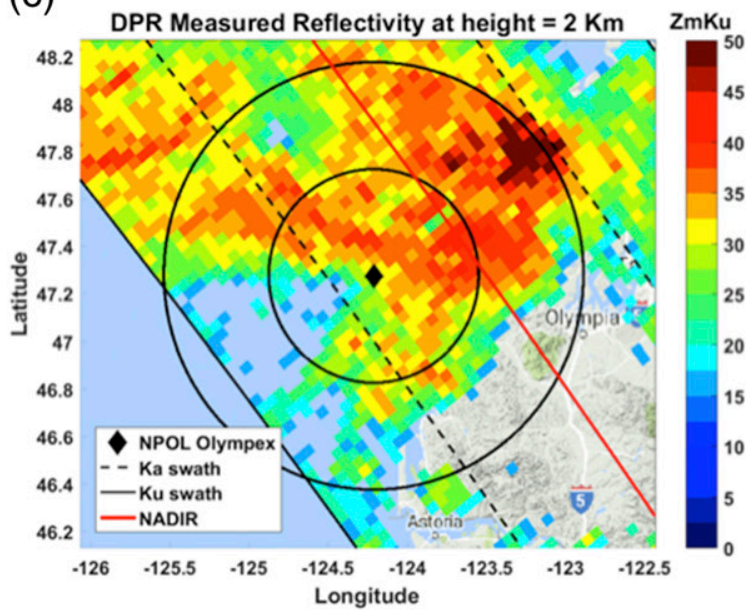

(b)

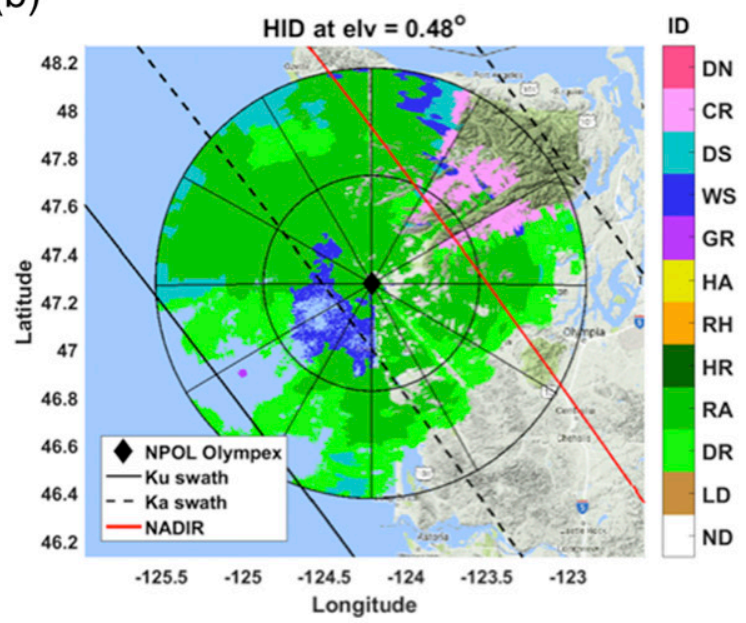

(d)

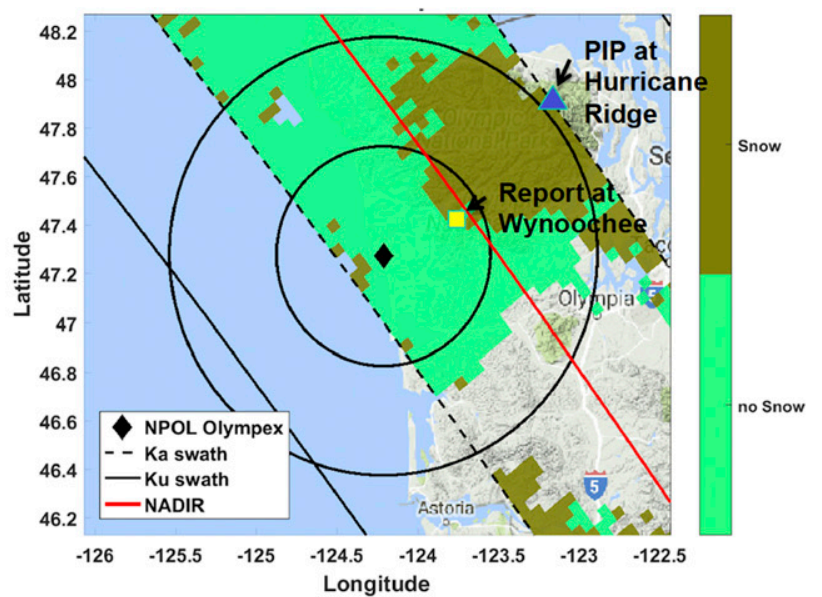

(e)

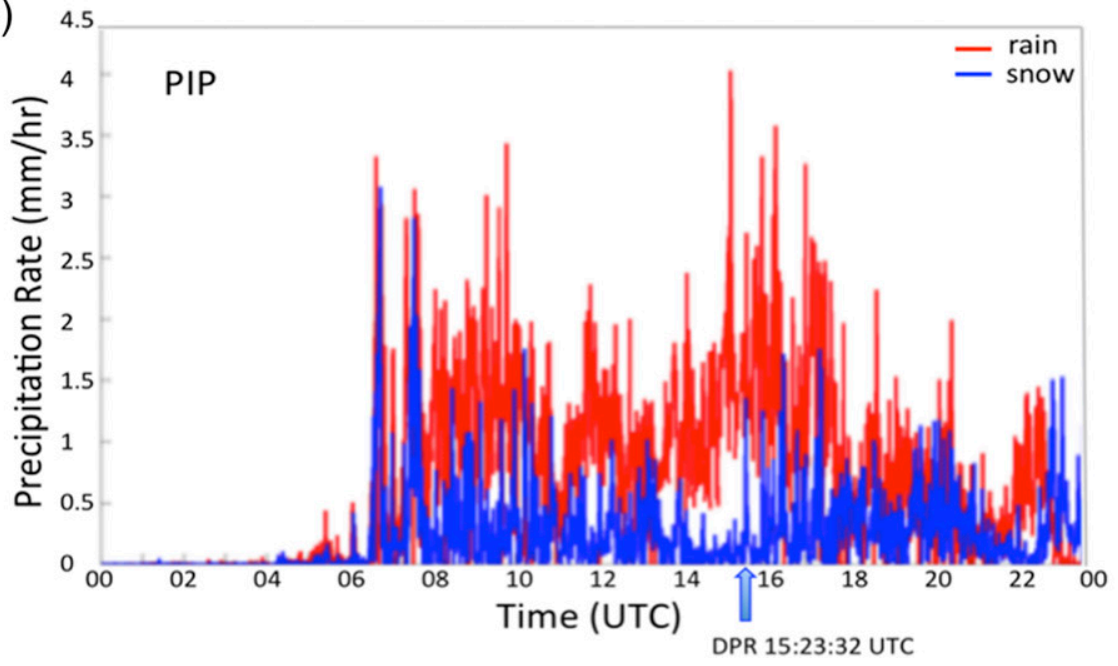

FIG. 7. Precipitation event observed by both GPM DPR overpass 10019 and NPOL on 3 Dec 2015 during OLYMPEX. The meaning of the lines is the same as in Fig. 3. (a) NPOL reflectivity at PPI of $0.48^{\circ}$. (b) Hydrometeor type for the scan in (a). (c) DPR reflectivity at outer swath at 2-km height. The time is 1523:32 UTC. (d) Surface snowfall flag. Blue triangle is the location of PIP image at Hurricane Ridge. (e) Precipitation rates from the PIP at Hurricane Ridge from 0000:00 to 2359:59 UTC 3 Dec 2015. 


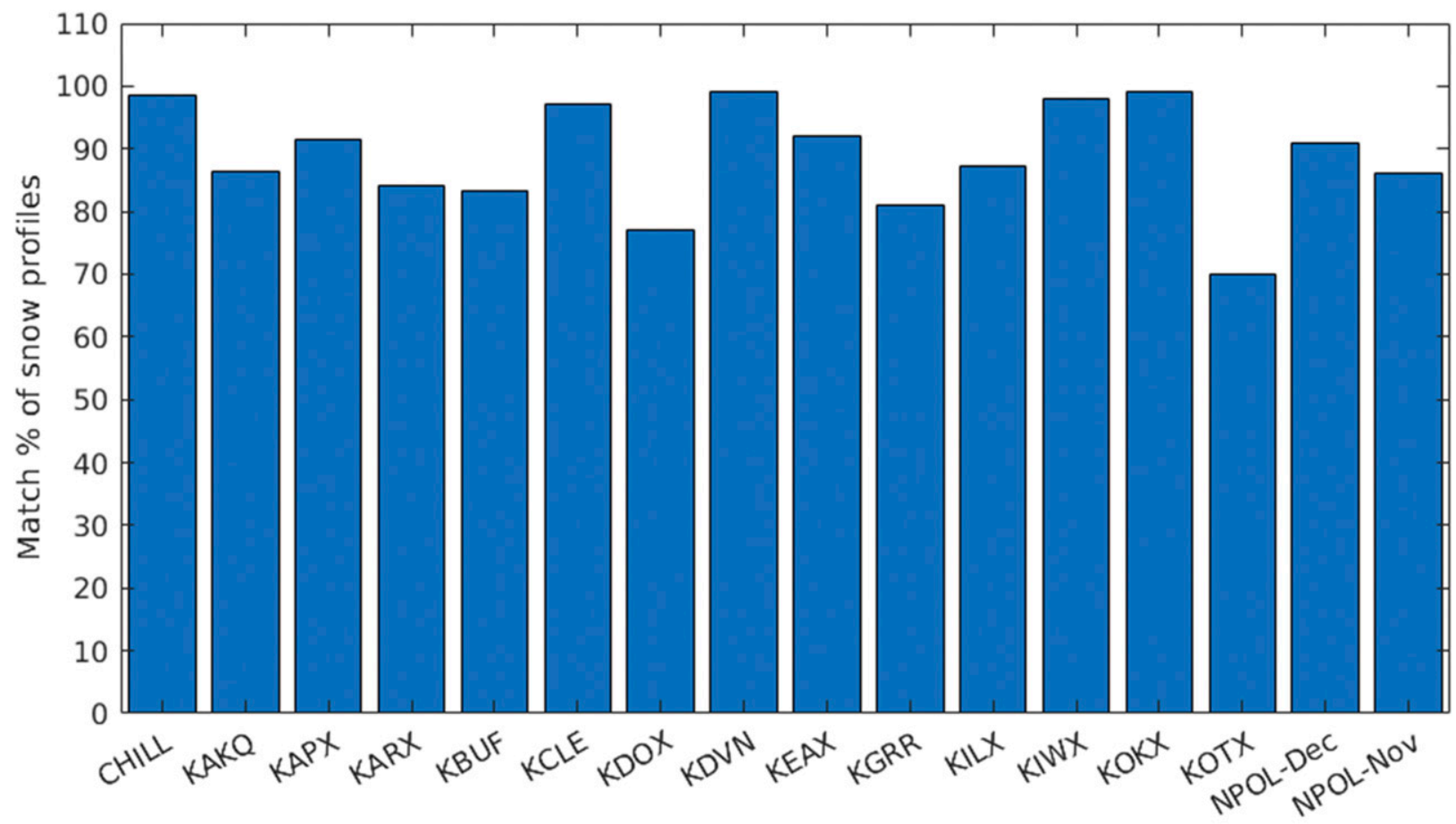

Ground radar name

FIG. 8. Match ratio for 16 validation cases during the year 2014-18.

with NPOL along the coastline. All the definitions of lines and circles in the plot follow the same rule as in previous cases. Figure $9 \mathrm{~b}$ is the surface snowfall flag showing snow everywhere in the overlap region. The PIP is located at Hurricane Ridge, illustrated by a blue triangle in Fig. 9b. The precipitation rate plot of PIP in Fig. 9c is showing almost all snowfall that day including the time of DPR flew by. So does the ground site report from Waterhole (yellow square in Fig. 9b), where 11 in. of new snow were reported on 14 November 2015 (see OLYMPEX portal). These ground truths at their locations match with the findings in Fig. $9 \mathrm{~b}$.

However, when we take a close look at the NPOL observations, we find brightband signatures at around $13-25-\mathrm{km}$ range to the NPOL at azimuth angle of $45.9^{\circ}$ (marked by a yellow cross in Fig. 9b). The bright band is observed at very low altitude around 1-km height about 11 min earlier than the time DPR flew over (1252:10 UTC). Figure 9d shows the RHI scan at azimuth angle of 45.9 (yellow line in Fig. 9b). At the circled location, reflectivity reaches peak values and brightband features exist. Below the bright band, the precipitation type at surface should not be snow. The NASA aircraft DC- 8 is used to mimic the satellite measurements by flying above cloud with onboard Airborne Precipitation Radar Third Generation (APR3) during OLYMPEX (Houze et al. 2017). APR3 flew over the campaign site starting at 1700:00 UTC. Although it is $4 \mathrm{~h}$ later than the GPM overpass in Fig. 9a, it still provides us some clues. Figure 9e is a vertical cut of the APR3 reflectivity at $\mathrm{Ku}$ band at nadir along the pink arrow track shown in Fig. 9b. APR3 radar has much finer vertical resolution of $29 \mathrm{~m}$ than DPR. Around scan number 5240 5270 (marked by pink cross in Fig. 9b), obvious bright band can be spotted at around $1 \mathrm{~km}$. At these two locations, the surface snowfall flag in Fig. 9b does not match with radar observations from NPOL and APR3.

The surface snowfall identification is based on studying the vertical profiles of $\mathrm{Ku}$ and $\mathrm{Ka}$ band from storm top toward the surface. To avoid the instability of the algorithm due to the clutter contamination, we calculate

TABLE 3. Average match ratio for validation cases under different surface type.

\begin{tabular}{lccrr}
\hline \multicolumn{1}{c}{ Surface type } & Flatland & Coastline & Lake & Mountain \\
\hline Total valid points & 2498 & 3338 & 2668 & 298 \\
Average match ratio in \% & 85.6 & 86.3 & 90.8 & $98.5($ one case) \\
\hline
\end{tabular}


(a)

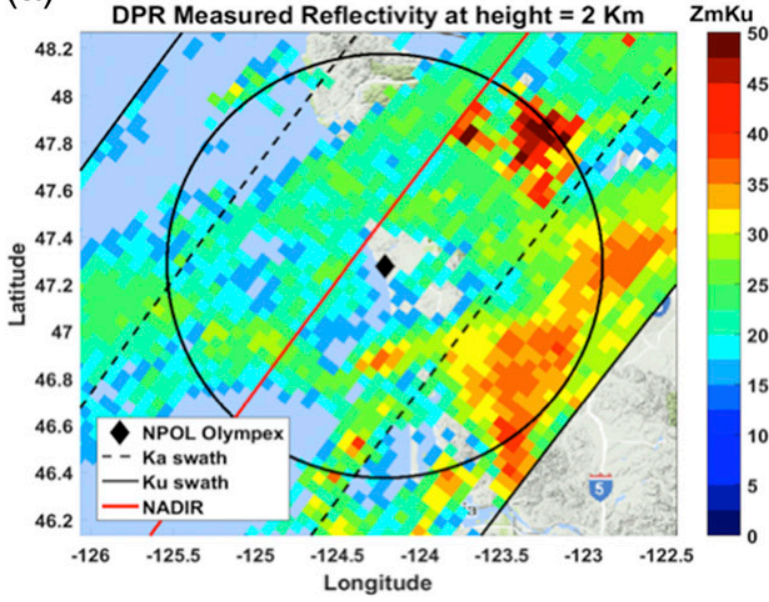

(b)

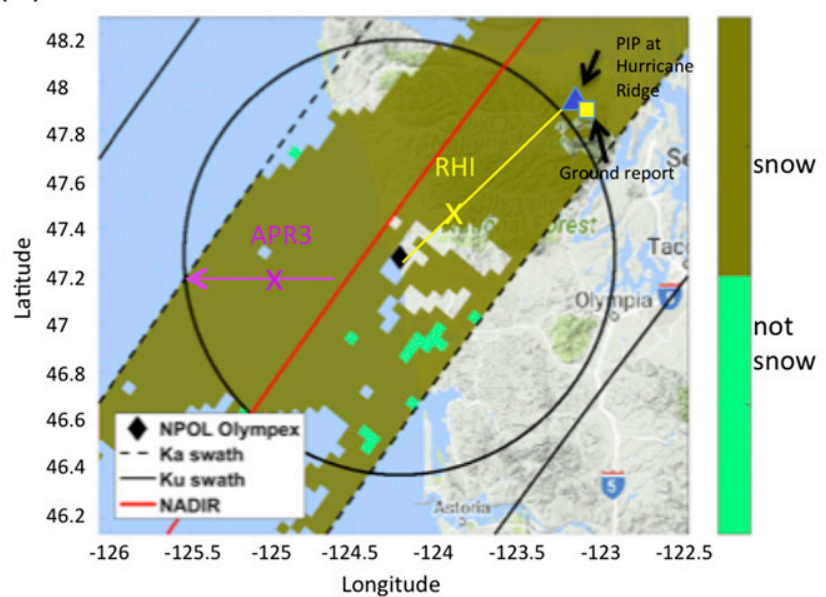

(c)

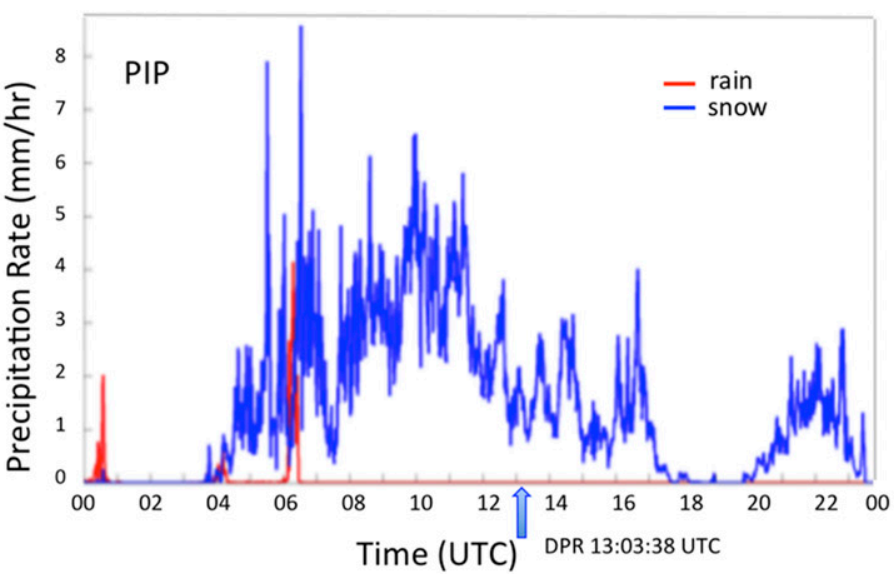

(d)

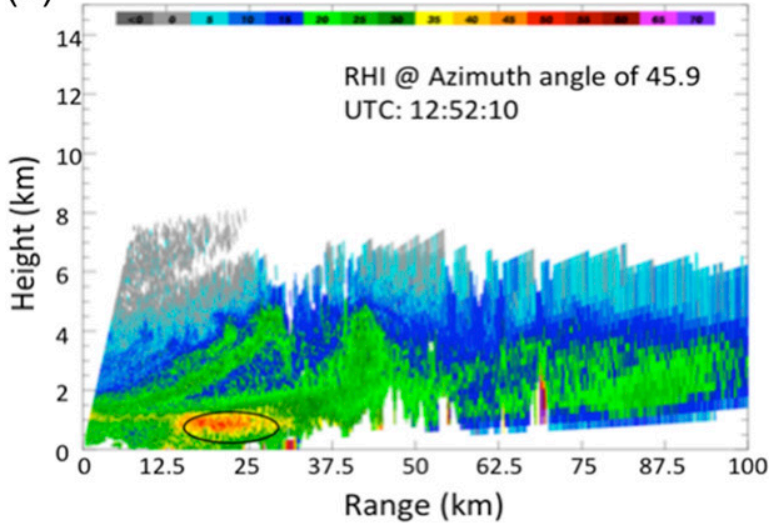

(e)

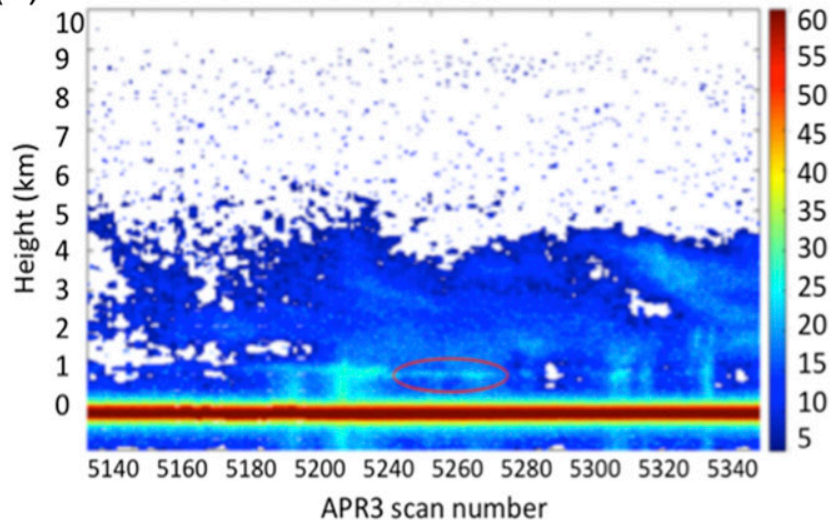

FIG. 9. Precipitation event observed by both GPM DPR overpass 9722 and NPOL on 14 Nov 2015 during OLYMPEX. (a) DPR reflectivity at outer swath at 2-km height. Time is 1303:38 UTC. The definition of the lines is the same as in Fig. 3. (b) Surface snowfall flag for the DPR overpass in (a). Yellow line is the direction of the RHI scan from NPOL at azimuth of $45.9^{\circ}$. Pink arrow illustrates APR3 flight track. Blue triangle is the location of PIP. Yellow square is the location of the ground report. (c) Precipitation rates from the PIP at Hurricane Ridge from 0000:00 to 2359:59 UTC 14 Nov 2015. (d) Reflectivity at S band for NPOL RHI scan at azimuth angle of $45.9^{\circ}$. (e) Vertical cut of $\mathrm{Ku}$ band reflectivity at nadir for APR3 radar along the track shown in (b). The $x$ axis represents the scan number for APR3 radar. 


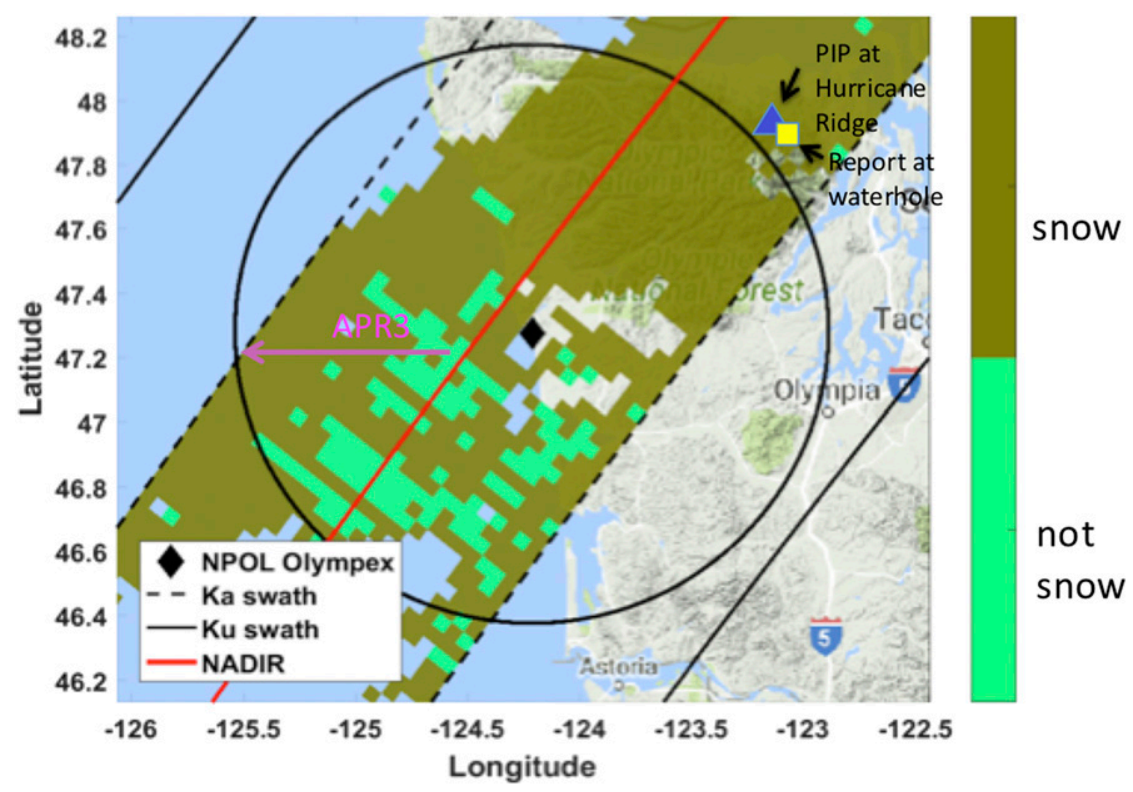

FIG. 10. Surface snowfall flag considering shallow precipitation situation.

the snow index based on range bin from storm top to three bins above the clutter free. In the case above, melting happens at around $1 \mathrm{~km}$, roughly four bins above sea level. The surface snowfall identification algorithm has difficulty catching the information of melting and thus puts out the wrong flag.

To decrease the misclassification for shallow precipitation, especially when bright band is within several range bins to surface clutter, we tried to modify the algorithm to use the brightband flag from $\mathrm{Ku}$ band to detect shallow precipitation. Figure 10 illustrates the snow flag plot after this modification. We see some improvements along APR3 track, but mismatch still exists at NPOL RHI scan. Another possibility to improve such a case is to push the algorithm to accept data points very close to surface clutter. However, we are not sure how this will affect the algorithm performance under normal conditions. The algorithm identification ability for precipitation with low bright band is one of the tasks for the future improvement.

\section{Summary}

Snow has become a more and more popular topic in the GPM era compared to TRMM, which is focused on a tropical area. The surface snowfall identification algorithm is newly implemented in the GPM DPR level-2 algorithm. Other than the algorithms relying on temperature, this algorithm is a radar-only algorithm mainly based on vertical profiles of reflectivity at $\mathrm{Ku}$ and $\mathrm{Ka}$ band to perform surface snowfall detection.
Ground validation is an essential part of space radar algorithm development and improvements in the GPM mission. Compared to the previous papers focused on the algorithm, this paper performs a detailed and thorough validation of the algorithm using different ground radars at different geophysical conditions including lake, mountain, coastline, and flatland in the last four years. These validation radars are NEXRAD, NASA NPOL, and CSU-CHILL radar. Meanwhile, validation cases at different seasons of the year are selected in order to test the stability of the algorithm. During the OLYMPEX campaign, other validation sources such as PIP imager and ground site reports are included in the cross-validation activity.

Among those successful validation cases shown in Table 1, a sample case is selected to illustrate the performance of the algorithm in each of the four surface types. In the flatland, lake, mountain and coastline cases, the fuzzy logic-based hydrometeor identification algorithm for dual-polarized ground radar shows great match with the vertical profile-based DPR algorithm. This is a very promising result because these two algorithms are very different and developed only for their radar systems. The match of snow region in the mountain case in April demonstrates the algorithm detectability of snowfall in the spring season. In OLYMPEX cases, ground truth such as PIP images and ground reports add strong evidence to the cross-validation results.

Statistical analysis is performed for all 16 cases. The match ratio is calculated within overlapped area between DPR and ground radar. Averaged match ratio is about 
$87.8 \%$ for 16 cases. Lake and mountain cases have higher match ratio at $90.8 \%$ and $98.5 \%$. Out of 16 cases, 11 have this ratio higher than $85 \%$. These are promising results.

The surface snowfall identification algorithm has limited detection ability for precipitation with low bright band mainly due to the intrinsic limitation of space radar resolution. This paper also discusses the limitation and potential modifications. Future work is needed to further improve this situation.

Acknowledgments. This research is supported by the NASA GPM/PMM program. Thanks to Sounak Biswas for identifying the validation cases.

\section{REFERENCES}

Bechini, R., and V. Chandrasekar, 2015: A semisupervised robust hydrometeor classification method for dual-polarization radar applications. J. Atmos. Oceanic Technol., 32, 22-47, https:// doi.org/10.1175/JTECH-D-14-00097.1.

Casella, D., G. Panegrossi, P. Sano, A. C. Marra, S. Dietrich, B. T. Johnson, and M. S. Kulie, 2017: Evaluation of the GPM-DPR snowfall detection capability: Comparison with CloudSat-CPR. Atmos. Res., 197, 64-75, https://doi.org/10.1016/ j.atmosres.2017.06.018.

Chandrasekar, V., and M. Le, 2017: Review of dual-frequency profile classification module and further improvements. Int Geoscience and Remote Sensing Symp., Fort Worth, TX, IEEE, 2716-2719, https://doi.org/10.1109/IGARSS.2017.8127557. , A. Hou, E. Smith, V. N. Bringi, S. A. Rutledge, E. Gorgucci, W. A. Petersen, and G. Skofronick Jackson, 2008: Potential role of dual-polarization radar in the validation of satellite precipitation measurements: Rationale and opportunities. Bull. Amer. Meteor. Soc., 89, 1127-1145, https://doi.org/10.1175/ 2008BAMS2177.1.
Heymsfield, A., A. Bansemer, N. B. Wood, G. Liu, S. Tanelli, O. O. Sy, M. Poellot, and C. Liu, 2018: Toward improving ice water content and snow-rate retrievals from radars. Part II: Results from three wavelength radar-collocated in-situ measurements and CloudSat-GPM-TRMM radar data. J. Appl. Meteor. Climatol., 57, 365-389, https://doi.org/10.1175/JAMC-D-17-0164.1.

Hou, A. Y., and Coauthors, 2014: The Global Precipitation Measurement Mission. Bull. Amer. Meteor. Soc., 95, 701-722, https:// doi.org/10.1175/BAMS-D-13-00164.1.

Houze, R. A., Jr., and Coauthors, 2017: The Olympic Mountains Experiment (OLYMPEX). Bull. Amer. Meteor. Soc., 98, 21672188, https://doi.org/10.1175/BAMS-D-16-0182.1.

Le, M., and V. Chandrasekar, 2013: Hydrometeor profile characterization method for Dual-Frequency Precipitation Radar onboard the GPM. IEEE Trans. Geosci. Remote Sens., 51, 36483658, https://doi.org/10.1109/TGRS.2012.2224352.

__ —_, and S. Biswas, 2017: An algorithm to identify surface snowfall from GPM DPR observations. IEEE Trans. Geosci. Remote Sens., 55, 4059-4071, https://doi.org/10.1109/ TGRS.2017.2687420.

OLYMPEX, 2015: OLYMPEX: A NASA/GPM ground validation field campaign in the Pacific Northwest. University of Washington, http://olympex.atmos.washington.edu/ index.html? $\mathrm{x}=$ Home.

Skofronick-Jackson, G., and Coauthors, 2015: Global Precipitation Measurement Cold Season Precipitation Experiment (GCPEx): For measurement's sake, let it snow. Bull. Amer. Meteor. Soc., 96, 1719-1741, https://doi.org/10.1175/BAMS-D-13-00262.1.

von Lerber, A. V., D. Moisseev, D. A. Marks, W. Petersen, A. Harri, and V. Chandrasekar, 2018: Validation of GMI snowfall observations by using a combination of weather radar and surface measurements. J. Appl. Meteor. Climatol., 57, 797820, https://doi.org/10.1175/JAMC-D-17-0176.1.

Wood, N., T. S. L'Ecuyer, A. J. Heymsfield, G. L. Stephens, D. R. Hudak, and P. Rodriguez, 2014: Estimating snow microphysical properties using collocated multisensor observations. J. Geophys. Res. Atmos., 119, 8941-8961, https://doi.org/ 10.1002/2013JD021303. 